\title{
Effects of Sedation and/or Sedation/Analgesic Drugs Administered during Central Venous Catheterization on the Level of End-tidal Carbon Dioxide Measured by Nasal Cannula in Our PICU
}

\author{
Nagehan Aslan ${ }^{1}$, Dincer Yildizdas², Ozden Ozgur Horoz ${ }^{3}$, Didar Arslan ${ }^{4}$, Yasemin Coban ${ }^{5}$, Yasar Sertdemir ${ }^{6}$
}

\begin{abstract}
Aims and objectives: Sedatives and analgesics are commonly used in pediatric intensive care units during minor invasive procedures. Here, we aimed to measure the changes in end-tidal carbon dioxide $\left(\mathrm{EtCO}_{2}\right)$ levels with different sedation/analgesic drug administrations (midazolam, ketamine, midazolam + ketamine/fentanyl) during central venous catheterization.

Materials and methods: This prospective study included 44 patients who needed sedation/analgesia for central venous catheterization. Patients were sedated with midazolam, ketamine, or midazolam + fentanyl/ketamine. End-tidal carbon dioxide values were measured before and after sedation-analgesia with nasal cannula and recorded from the capnograph. Oxygen saturation $\left(\mathrm{SO}_{2}\right)$ was monitored by pulse oximetry. Whether respiratory depression occurred during the process was recorded.

Results: During the procedure, 15 (34\%) patients were given $0.1 \mathrm{mg} / \mathrm{kg}$ dose of midazolam described as group I, 18 (41\%) patients were given 1 $\mathrm{mg} / \mathrm{kg}$ dose of ketamine only described as group II, and 11 (25\%) patients who could not be effective sedated with a single sedative-analgesic agent were given either $1 \mathrm{mg} / \mathrm{kg}$ dose of ketamine or $2 \mu \mathrm{g} / \mathrm{kg}$ dose of fentanyl together with $0.1 \mathrm{mg} / \mathrm{kg}$ dose of midazolam described as group III. According to our findings, hypoxia (54.5\%) and hypercarbia (45.5\%) were detected higher in group III but it was not statistically significant $(p=$ $0.255, p=0.364$ ). Hypercarbia was detected in $29.5 \%$ patients, in $62 \%$ of these patients hypercarbia was accompanied by hypoxia, and $38 \%$ had only hypercarbia. When presedation and postsedation $\mathrm{EtCO}_{2}$ values were compared, we detected a statistically significant difference in all groups. Conclusion: We detected hypercarbia unaccompanied by hypoxemia in $38 \%$ patients. And we think that we have identified these patients early due to measurement of $\mathrm{EtCO}_{2}$ by nasal cannula. This study demonstrated that $\mathrm{EtCO}_{2}$ monitoring via nasal cannula is a feasible and practical way to follow ventilation during sedation/analgesia.

Keywords: Analgesia, Capnography, End-tidal carbon dioxide, Pediatric intensive care, Sedation.

Indian Journal of Critical Care Medicine (2020): 10.5005/jp-journals-10071-23529
\end{abstract}

\section{INTRODUCTION}

Sedatives and analgesics are commonly used in pediatric patients during minor invasive procedures to reduce pain and anxiety and provide ease of process. ${ }^{1}$ All sedatives-analgesics have significant side effects, such as respiratory depression, bradycardia, and hypotension. ${ }^{2}$ Monitoring of patients who were given sedativesanalgesics is critical both during and after the procedure. ${ }^{3}$ Standard monitoring is performed with a pulse oximeter. ${ }^{4}$ Capnography is the process of measuring carbon dioxide $\left(\mathrm{CO}_{2}\right)$ partial pressure in the airway during respiration. End-tidal carbon dioxide $\left(\mathrm{EtCO}_{2}\right)$ is the maximum value obtained at the end expiration. Capnograph is the device that shows $\mathrm{CO}_{2}$ value against time or volume in graph. ${ }^{5}$ Utilization of capnography has been increasing recently in many fields, particularly in procedural sedation analgesia in the emergency departments and pediatric intensive care units (PICU), and also in the evaluation of cardiopulmonary resuscitation events and ventilation monitoring in unconscious patients. ${ }^{6}$ Two different types of measurements, namely mainstream and sidestream, are made with capnographs. In mainstream measurement method, a sensor is placed on the patient's airway and measurements are made directly; it is used commonly for the verification of intubation in intubated patients and for ventilation monitoring. In the sidestream measurement method, breath sample is taken
${ }^{1-6}$ Department Pediatric Intensive Care, Faculty of Medicine, Çukurova University, Adana, Turkey; Department of Biostatistics, Cukurova University Faculty of Medicine, Çukurova University, Adana, Turkey

Corresponding Author: Nagehan Aslan, Department Pediatric Intensive Care, Faculty of Medicine, Çukurova University, Adana, Turkey; Department of Biostatistics, Cukurova University Faculty of Medicine, Çukurova University, Adana, Turkey, Phone: +90 50554999 86, e-mail: nagehan_aslan@hotmail.com

How to cite this article: Aslan N, Yildizdas D, Horoz OO, Arslan D, Coban Y, Sertdemir Y. Effects of Sedation and/or Sedation/Analgesic Drugs Administered during Central Venous Catheterization on the Level of End-tidal Carbon Dioxide Measured by Nasal Cannula in Our PICU. Indian J Crit Care Med 2020;24(8):705-708.

Source of support: Nil

Conflict of interest: None

from the respiration air with nasal cannula and measurement is made indirectly. Carbon dioxide measurement can be easily made with a nasal cannula when the patient is not intubated and breathing frequency and depth of the patient can be continuously monitored. ${ }^{7}$ Decrease in breathing pattern or increase in $\mathrm{EtCO}_{2}$ amount in the capnogram is interpreted as respiratory depression. ${ }^{8}$ 
It has been reported in previous studies that capnography is a tool that can be used safely in monitoring of the sedation-analgesia related side effects. ${ }^{1,3-5}$

The purpose of our study was to determine the effects of sedation-analgesia drugs administered during central venous catheterization performed in our tertiary care PICU on the $\mathrm{EtCO}_{2}$ levels measured by nasal cannula and to determine the risk of inducing respiratory depression of different sedation-analgesia applications.

\section{Materials and Methods}

Forty-four pediatric patients who were inserted central venous catheter and were administered sedation-analgesia, meanwhile in the PICU of Cukurova University Faculty of Medicine, between June 2018 and September 2018 were prospectively included in the study. Patients with severe systemic diseases, pulmonary, liver, or renal failure and patients with a history of allergic reaction to sedative-analgesics were excluded from the study. End-tidal carbon dioxide values were measured before and after sedation-analgesia with nasal cannula (Oridion, Capnostream) and were recorded from the capnograph. Patient oxygen saturation $\left(\mathrm{SO}_{2}\right)$ was monitored by pulse oximetry. Whether respiratory depression occurred during the process was recorded. Respiratory depression was defined in two ways as hypercarbia and hypoxia. Hypercarbia was regarded as $>10 \mathrm{~mm} \mathrm{Hg}$ increase in the postsedation $\mathrm{EtCO}_{2}$ level compared to presedation $\mathrm{EtCO}_{2}$ level. ${ }^{9}$ Hypoxia was considered as $\mathrm{SO}_{2}$ being $<92 \% .{ }^{10}$ Patients were sedated with midazolam ( $0.1 \mathrm{mg} / \mathrm{kg}$ dose) or ketamine $(1 \mathrm{mg} / \mathrm{kg})$ or midazolam + fentanyl $(2 \mu \mathrm{g} / \mathrm{kg})$ or ketamine ( $1 \mathrm{mg} / \mathrm{kg}$ ). Central venous catheterization performed by pediatric intensive care fellows. Sedative-analgesia application changed to the clinical approach and experience of the fellow who inserted central venous catheter. The nasal cannula was well tolerated in all patients. The study was performed in accordance with the 1964 Declaration of Helsinki ethical criteria and was approved by Cukurova University School of Medicine, Clinical Study Ethics Committee. Written informed consent was obtained from the families of patients.

\section{Statistical Analysis}

IBM SPSS Statistics version 20.0 package program was used in the statistical analysis. Categorical measurements were summarized in numbers and percentages, whereas numerical measurements were summarized as mean and standard deviation (median and minimum-maximum where necessary). Chi-square test statistic was used in the comparison of categorical measurements between the groups. Mann-Whitney U test was used while comparing numerical measurements with non-normal distribution between two groups. Statistical significance level was determined as 0.05 in all tests.

\section{Results}

A total of 44 patients were included in the study, and their mean age was $6.3 \pm 5.4$ years. Twenty-three $(52 \%)$ of the patients were female. For the entire group, presedation $\mathrm{EtCO}_{2}$ was $30.11 \pm 5.75$ $\mathrm{mm} \mathrm{Hg}$, and postsedation $\mathrm{EtCO}_{2}$ was $35.55 \pm 7.33 \mathrm{~mm} \mathrm{Hg}$. During the procedure, 15 (34\%) patients were given $0.1 \mathrm{mg} / \mathrm{kg}$ dose of midazolam described as group I, 18 (41\%) patients were given $1 \mathrm{mg} /$ kg dose of ketamine only described as group II, and 11 (25\%) patients who could not be effectively sedated with a single sedativeanalgesic agent were given either $1 \mathrm{mg} / \mathrm{kg}$ dose of ketamine or
$1 \mathrm{~kg}$ dose of fentanyl together with $0.1 \mathrm{mg} / \mathrm{kg}$ dose of midazolam described as group III. There was no significant difference between the three groups in terms of age, gender, body weight, presedation the $\mathrm{EtCO}_{2}$, and postsedation $\mathrm{EtCO}_{2}$ values (Table 1). According to our findings, hypoxia (54.5\%) and hypercarbia (45.5\%) were detected higher in group III but it was not statistically significant $(p=0.255$, $p=0.364)$. Hypercarbia was detected in $13(29.5 \%)$ patients, in 8 (62\%) of these patients hypercarbia was accompanied by hypoxia, and 5 (38\%) had only hypercarbia. Postsedation $\mathrm{EtCO}_{2}$ was $35 \pm$ $8.1 \mathrm{~mm} \mathrm{Hg}$ in group I, $35.8 \pm 7.1 \mathrm{~mm} \mathrm{Hg}$ in group II, and $35.7 \pm 7.1$ $\mathrm{mm} \mathrm{Hg}$ in group III (Fig. 1). When presedation and postsedation $\mathrm{EtCO}_{2}$ values were compared, a statistically significant difference was detected in all three groups and $p$ values in each group were, respectively, $p=0.024, p<0.001$, and $p=0.003$ (Fig. 2). A severe decrease in postsedation $\mathrm{EtCO}_{2}$ levels was seen only in one patient in the midazolam group and the same patient was given tactile stimulation due to apnea development. None of the patients needed bag valve mask ventilation or intubation.

\section{Discussion}

Capnometry is a routinely used noninvasive assessment technique that allows for the rapid and efficient monitoring of ventilation, circulation, and metabolism. ${ }^{11}$ Sedation-analgesia is widely used during minor procedures which monitoring is crucial. American Academy of Pediatrics recommends the standard practice of monitoring $\mathrm{EtCO}_{2}$ levels with capnography during deep sedation. ${ }^{12}$

Table 1: Comparison of presedation and postsedation $\mathrm{EtCO}_{2}$ values and demographic characteristics of the groups

\begin{tabular}{lcccl}
\hline & $\begin{array}{l}\text { Group Imean } \\
\pm S D\end{array}$ & $\begin{array}{l}\text { Group II mean } \\
\pm S D\end{array}$ & $\begin{array}{l}\text { Group III } \\
\text { mean } \pm S D\end{array}$ & pvalue \\
\hline $\begin{array}{l}\text { Age (years) } \\
\text { Body weight } \\
\text { (kg) }\end{array}$ & $7.19 \pm 5.59$ & $6.45 \pm 5.19$ & $4.9 \pm 5.78$ & 0.54 \\
$\begin{array}{l}\text { Presedation } \\
\text { EtCO }\end{array}$ (mm & $32.66 \pm 18.13$ & $20.36 \pm 14.72$ & $19.54 \pm 18.95$ & 0.61 \\
$\mathrm{Hg})$ & & $29 \pm 5.57$ & $28.45 \pm 6.12$ & 0.07 \\
$\begin{array}{l}\text { Postsedation } \\
\mathrm{EtCO}_{2} \text { (mm }\end{array}$ & $35.07 \pm 8.17$ & $35.83 \pm 7.14$ & $35.73 \pm 7.11$ & 0.98 \\
$\mathrm{Hg})$ & & & & \\
\hline
\end{tabular}

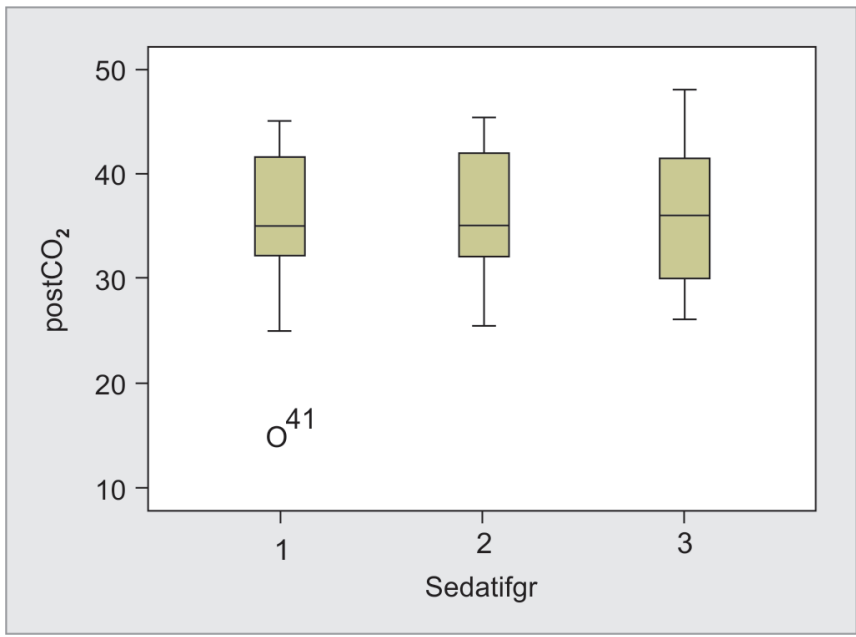

Fig. 1: Postsedation $\mathrm{EtCO}_{2}$ values of the groups 


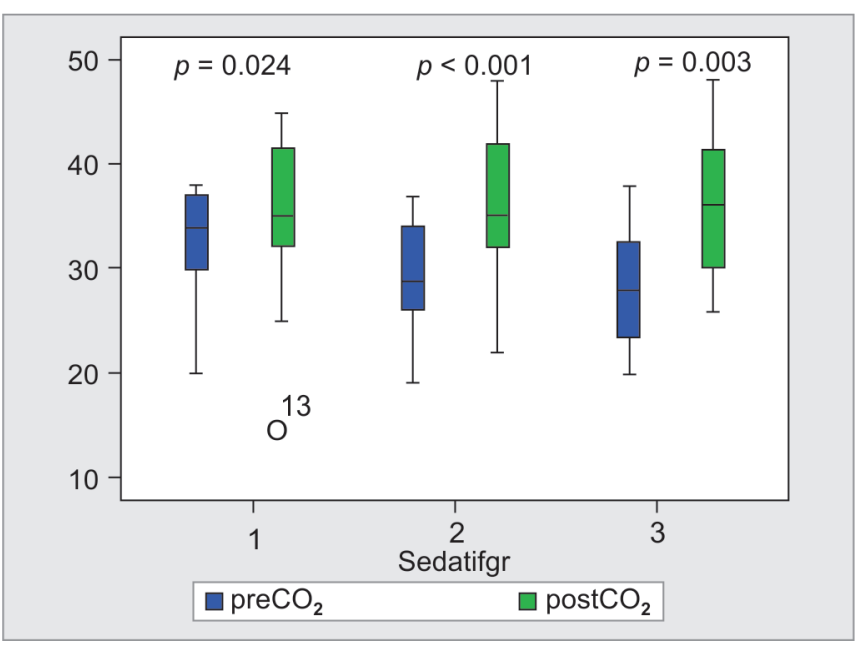

Fig. 2: Comparison of presedation and postsedation $\mathrm{EtCO}_{2}$ values for each group

Many studies have demonstrated that capnography is a reliable indicator and a useful diagnostic tool in identifying respiratory depression induced by sedation-analgesia., ${ }^{1,13}$ Compared to the use of pulse oximetry, capnography identifies respiratory depression in the earlier period. ${ }^{12}$ As we know, hypoxia is a relatively late finding compared to hypercarbia in respiratory depression. ${ }^{14}$ Oxygen saturation can be measured within the normal range for several minutes even when respiratory depression occurs in patients who are receiving oxygen. ${ }^{14,15}$ With capnograph, hypercarbia can be detected before hypoxia and it allows performing necessary interventions, such as withdrawing sedation, or giving stimulation to the patient. ${ }^{16}$

Langhan et al. ${ }^{17}$ in their study in which they used nasal capnography monitoring during the invasive procedures which required sedation-analgesia in the pediatric emergency department have suggested that capnography is a superior means of detecting all kinds of hypoventilation. In the United States, noninvasive capnography monitoring was used in children receiving sedation-analgesia during 174 endoscopies carried out on 163 pediatric patients and it was suggested that capnography detected alveolar hypoventilation in the early periods in sedations administered during invasive procedures and that it was effective in early detection and prevention of hypoxemia. ${ }^{18}$ In a neonatal study reported from Israel, nasal $\mathrm{EtCO}_{2}$ were measured in 20 preterm, and 39 term infants in the prone and supine positions and it was demonstrated that measurements can be made in both positions and the measurements are consistent with each other..$^{19}$ In another study from Taiwan, 34 newborns followed up for respiratory distress were monitored with nasal capnography and a significant correlation between $\mathrm{EtCO}_{2}$ and partial $\mathrm{CO}_{2}$ in arterial blood gases was reported and the importance of the method was emphasized. ${ }^{20}$ In the study by Flanagan and Tobias, ${ }^{21} \mathrm{EtCO}_{2}$ measurements were made with nasal cannula in spontaneous breathing and it was determined that hypoventilation was characterized by an increase in the $\mathrm{EtCO}_{2}$ levels. They reported that hypoxia was a later finding in the respiratory depression compared to hypercarbia. Yildizdas et al. $^{22}$ have detected hypoxia and hypercarbia in $3.2 \%$ of the patients, while hypercarbia was detected in $16.6 \%$ of the patients. According to this result, they emphasized the use of capnography during sedation-analgesia by saying that they could have identified respiratory depression in only 4 of these 21 patients if they had been using only pulse oximetry monitoring. In our study, we detected hypercarbia unaccompanied by hypoxemia in five (38\%) patients. And we think that we would have identified these patients later if we also were using only the pulse oximetry monitoring.

Similar to our study, Hart et al. ${ }^{23}$ detected $20 \%$ respiratory depression in the fentanyl group, and $23 \%$ in the midazolam + fentanyl group. Tobias ${ }^{24}$ reported $6 \%$ hypoxia in their where they used midazolam + ketamine. McQuillen and Steele ${ }^{1}$ divided patients into groups of midazolam, midazolam + ketamine, and midazolam + fentanyl; and they reported the highest increase in the $\mathrm{EtCO}_{2}$ levels in group III. We divided patients into three groups in our study as midazolam, ketamine, midazolam + ketamine/ fentanyl groups, as well. We detected hypoxia and hypercarbia higher in the group III, even though it was statistically insignificant. Statistically significant differences were detected in all three groups when presedation and postsedation $\mathrm{EtCO}_{2}$ values were compared. A severe decrease in postsedation $\mathrm{EtCO}_{2}$ levels was seen only in one patient in the midazolam group and the same patient required to be given tactile stimulation due to apnea development. None of our patients required bag valve mask ventilation or intubation.

Reinhold and Graichen ${ }^{25}$ did not detect $\mathrm{EtCO}_{2}$ increase in the group given propofol for magnetic resonance imaging. Hertzog et al. ${ }^{26}$ detected respiratory depression at the rate of $30 \%$ in the group given propofol during cardioversion. Yildizdas et al. ${ }^{22}$ detected increase in $\mathrm{EtCO}_{2}$ levels and hypoventilation, particularly in the group given propofol and reported that they consider that propofol might not be the first choice for short-term procedures. Based on the results of this study previously performed in our unit, we do not often prefer the use propofol for minor procedures in our clinical practices. Therefore, our study does not have the propofol group.

The main limitation of our study is the low number of patients. Also, the fact that bispectral index monitoring or sedationanalgesia scale measurement was not performed on our patients is another limitation.

In conclusion, we all know the incidence of subclinical respiratory depression in patients undergoing sedation-analgesia is greater than expected. In the present study, we detected hypercarbia unaccompanied by hypoxemia in $38 \%$ patients. And we think that we have identified these patients in the early period due to measurement of $\mathrm{EtCO}_{2}$ by nasal cannula in addition to standard pulse oximetry monitorization. End-tidal carbon dioxide monitoring with nasal cannula is a useful monitoring tool for assessing sedation or sedation-analgesia during ventilation in pediatric patients. While further studies with larger groups of patients are necessary to evaluate the efficacy of capnography, we think that capnography will improve the quality of care of children during sedation and that it is crucial for the early detection of respiratory depression and for the necessary interventions to be made.

\section{References}

1. McQuillen KK, Steele DW. Capnography during sedation/analgesia in the pediatric emergency department. Pediatr Emerg Care 2000;16(6):401-404. DOI: 10.1097/00006565-200012000-00005.

2. Jagoda AS, Campbell M, Karas S, Mariani PJ, Shepherd SM, Cantrill SV, et al. Clinical policy for procedural sedation and analgesia in the emergency department. Ann Emerg Med 1998;31(5):663-677. DOI: 10.1016/S0196-0644(98)70216-1.

3. Waugh JB, Epps C, Khodneva Y. Capnography enhances surveillance of respiratory events during procedural sedation: a meta-analysis. J Clin Anesth 2011;23(3):189-196. DOI: 10.1016/j.jclinane.2010.08.012. 
4. Radaelli F, Terruzzi V, Minoli G. Extended/advanced monitoring techniques in gastrointestinal endoscopy. Gastrointest Endosc Clin N Am 2004;14(2):335-352. DOI: 10.1016/j.giec.2004.01.008.

5. Nagler J, Krauss B. Capnography: a valuable tool for airway management. Emerg Med Clin North Am 2008;26(4):881-897. DOI: 10.1016/j.emc.2008.08.005.

6. Krauss B, Hess DR. Capnography for procedural sedation and analgesia in the emergency department. Ann Emerg Med 2007;50(2):172-181. DOI: 10.1016/j.annemergmed.2006.10.016.

7. Güngör G, Adıgüzel N. Mekanik ventilasyon sırasında solunum monitörizasyonu. Mekanik Ventilasyon, İstanbul, Probiz yayıncılık 2013. 203-224.

8. Meliones J, Wilson BG, Cheifetz PM. Respiratory monitoring. In: Rogers MC, ed. Textbook of Pediatric Intensive Care. 3rd ed., Baltimore: Williams \& Wilkins; 1996. pp. 331-363.

9. Miner JR, Biros MH, Heegaard W, Plummer D. Bispectral electroencephalographic analysis of patients undergoing procedural sedation in the emergency department. Acad Emerg Med 2003;10(6):638-643. DOI: 10.1111/j.1553-2712.2003.tb00048.x.

10. Sivilotti MLA, Messenger DW, van Vlymen J, Dungey PE, Murray HE. A comparative evaluation of capnometry vs pulse oximetry during procedural sedation and analgesia on room air. CJEM 2010;12(5): 397-404. DOI: 10.1017/S1481803500012549.

11. Kupnik D, Skok P. Capnometry in the prehospital setting: are we using its potential? Emerg Med J 2007;24(9):614-617. DOI: 10.1136/ emj.2006.044081.

12. American Academy of Pediatrics, Committee on Drugs. Guidelines for monitoring and management of pediatric patients during and after sedation for diagnostic and therapeutic procedures. Pediatrics 1992;89(6 Pt 1):1110-1115.

13. Wilson S, Farrel K, Griffen A, Coury D. Conscious sedation experiences in graduate pediatric dentistry programs. Pediatr Dent 2001;23(4):307-314.

14. Cacho G, Pérez-Calle JL, Barbado A, Lledó JL, Ojea R, FernándezRodríguez CM, et al. Capnography is superior to pulse oximetry for the detection of respiratory depression during colonoscopy. Rev Esp Enferm Dig 2010;102(2):86-89. DOI: 10.4321/S113001082010000200003.

15. Pandya NK, Sharma S. Capnography and pulse oximetry. Stat Pearls Publishing; 2019.
16. Patel R, Lenczyk M, Hannallah RS, McGill WA. Age and the onset of desaturation in apneic children. Can J Anaesth 1994;41(9):771-774. DOI: 10.1007/BF03011582.

17. Langhan ML, Shabanova V, Li FY, Bernstein SL, Shapiro ED. A randomized controlled trial of capnography during sedation in a pediatric emergency setting. Am J Emerg Med 2015;33(1):25-30. DOI: 10.1016/j.ajem.2014.09.050.

18. Lightdale JR, Goldmann DA, Feldman HA, Newburg AR, DiNardo $J A$, Fox VL. Microstream capnography improves patient monitoring during moderate sedation: a randomized, controlled trial. Pediatrics 2006;117(6):e1170-e1178. DOI: 10.1542/peds.2005-1709.

19. Kugelman A, Bilker A, Bader D, Cohen A, Tirosh E. Sidestream endtidal capnometry as related to infant's position and maturation. Acta Paediatr 2002;91(8):869-873. DOI: 10.1111/j.1651-2227.2002.tb02847.x.

20. Tai CC, Lu FL, Chen PC, Jeng SF, Chou HC, Chen CY, et al. Noninvasive capnometry for end-tidal carbon dioxide monitoring via nasal cannula in nonintubated neonates. Pediatr Neonatal 2010;51(6): 330-335. DOI: 10.1016/S1875-9572(10)60064-2.

21. Flanagan JFK, Tobias JD. Non-invasive monitoring of end-tidal $\mathrm{CO}_{2}$ by nasal cannula in spontaneously breathing children in the pediatric intensive care unit. Anesth Analg 1995;80:128.

22. Yildizdas D, Yapcoglu H, YLmaz HL. The value of capnography during sedation/analgesia in pediatric minor procedures. Pediatr Emerg Care 2004;20(3):162-165. DOI: 10.1097/01.pec.0000117922.65522.26.

23. Hart LS, Berns SD, Houck CS, Boenning DA. The value of end-tidal $\mathrm{CO}_{2}$ monitoring when comparing three methods of conscious sedation for children undergoing painful procedures in the emergency department. Pediatr Emerg Care 1997;13(3):188-192. DOI: 10.1097/00006565-199706000-00004.

24. Tobias JD. End-tidal carbon dioxide monitoring during sedation with a combination of midazolam and ketamine for children undergoing painful, invasive procedures. Pediatr Emerg Care 1999;15(3):173-175. DOI: 10.1097/00006565-199906000-00002.

25. Reinhold P, Graichen B. Propofol for sedation in pediatric magnetic resonance imaging investigations. Klin Pediatr 1999;211(1):40-43. DOI: $10.1055 / \mathrm{s}-2008-1043761$.

26. Hertzog HJ, Campbell JK, Dalton HJ, Cockerham JT, Hauser GJ. Propofol anesthesia for elective cardioversion of pediatric intensive care unit patients with congenital heart disease. J Intensive Care Med 1997;12(5):264-268. DOI: 10.1177/088506669701200507. 